\title{
THE INFLUENCE OF DESULFOVIBRIO DESULFURICANS ON NEPTUNIUM CHEMISTRY
}

\author{
L. SODERHOLM*, C.W. WLLIAMS*, MARK.R. ANTONIO*, MONICA LEE \\ TISCHLER** AND MICHAEL MARKOS** \\ *Chemistry Division, Argonne National Laboratory, Argonne, II, 60439. \\ Is@anl.gov, mantonio@anl.gov \\ **Department of Biological Sciences, Benedictine University, Lisle II
}

Abstract paper No. R14.3

Presented at the

1999 Fall Materials Research Society Meeting

29 November - 3 December

Boston MA

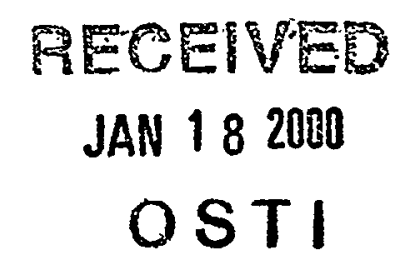

The submitted manuscript has been created by the University of Chicago as Operator of Argonne National Laboratory ("Argonne") under Contract No. W-31-109-ENG-38 with the U.S. Department of Energy. The U.S. Government retains for itself, and others acting on its behalf, a paid-up, nonexclusive, irrevocable worldwide license in said article

to reproduce, prepare derivative works, dis-

tribute coples to the public, and pertorm pub-

licly and display publicty, by or on behalf of

the Govemment. 


\section{DISCLAIMEŔ}

This report was prepared as an account of work sponsored by an agency of the United States Government. Neither the United States Government nor any agency thereof, nor any of their employees, make any warranty, express or implied, or assumes any legal liability or responsibility for the accuracy, completeness, or usefulness of any information, apparatus, product, or process disclosed, or represents that its use would not infringe privately owned rights. Reference herein to any specific commercial product, process, or service by trade name, trademark, manufacturer, or otherwise does not necessarily constitute or imply its endorsement, recommendation, or favoring by the United States Government or any agency thereof. The views and opinions of authors expressed herein do not necessarily state or reflect those of the United States Government or any agency thereof. 


\section{DISCLAIMER}

Portions of this document may be illegible in electronic image products. Images are produced from the best available original document. 
THE INFLUENCE OF DESULFOVIBRIO DESULFURICANS ON NEPTUNIUM CHEMISTRY

\author{
L. SODERHOLM*, C.W. WILLIAMS*, MARK.R. ANTONIO*, MONICA LEE TISCHLER** \\ AND MICHAEL MARKOS** \\ *Chemistry Division, Argonne National Laboratory, Argonne, IL, 60439. 노anl.gov, \\ mantonio@anl.gov \\ **Department of Biological Sciences, Benedictine University, Lisle $\mathbb{L}$
}

\title{
ABSTRACT
}

The role of biotic $N p(V)$ reduction is studied in light of its potential role in the environmental immobilization of this hazardous radionuclide. The speciation of $\mathrm{Np}$ in Desulfovibrio desulfuricans cultures is compared with Np speciation in the spent medium and in the uninoculated medium. Precipitates formed in all three samples. Optical spectroscopy and $\mathrm{x}-$ ray absorption near edge structure (XANES) were used to determine that $\mathrm{Np}(\mathrm{V})$ is almost quantitatively reduced in all three samples and that the precipitate is an amorphous $N p(I V)$ species. These results demonstrate that the reduction of $\mathrm{Np}$ is independent of Desulfovibrio desulfuricans. The underlying chemistry associated with these results is discussed.

\section{INTRODUCTION}

Neptunium (Np; atomic number 93) is a highly toxic, long-lived radionuclide that is abundant in nuclear waste. Like other light actinide elements, the chemistry of $\mathrm{Np}$ is complex and dependent upon speciation ${ }^{1}$. Under environmentally relevant conditions, $\mathrm{Np}$ can be found in the (III), (IV), (V), or (VI) oxidation states. In the laboratory, acidic $\mathrm{Np}$ solutions at low $\mathrm{pH}$ contain primarily the neptunyl $[\mathrm{O}=\mathrm{Np}(\mathrm{V})=\mathrm{O}]^{+}$ion. Whereas $\mathrm{Np}(\mathrm{V})$ and $(\mathrm{VI})$ are soluble in near neutral $\mathrm{pH}, \mathrm{Np}(\mathrm{IV})$ forms hydrous oxides or the dioxide, both of which are very insoluble. Therefore, in order to effectively model the fate and transport of $\mathrm{Np}$ in the environment, it is important to understand to what extent neptunyl can be reduced to an insoluble $\mathrm{Np}(\mathrm{IV})$ species, and to identify any mechanisms by which such a reduction can occur.

Although the redox chemistry of $\mathrm{Np}$ is predictable under controlled, laboratory conditions, the complexity of natural groundwaters, in terms of dissolved organics and inorganics, as well as the presence of bacteria and catalytic mineral surfaces, prohibits a predictive understanding of $\mathrm{Np}$ chemistry and redox speciation in all but the simplest systems. The reduction of uranyl(VD) to $\mathrm{UO}_{2}$ has been observed and understood in terms of an enzymatic reaction that is coupled to the electron-transport chains of metal-reducing bacteria ${ }^{2}, 3$. The bacteria involved in the reduction are well known as anaerobic iron, $\mathrm{Fe}(\mathrm{III})$, reducers. Thermodynamically, the uranyl(VI) ion is harder to reduce than either the $N p(V)$ ion or the $\mathrm{Fe}$ (III) ion, as evidenced by the standard reduction potentials listed in Table I.

A variety of microorganisms have been demonstrated to reduce uranium(VI) ${ }^{4}$ and $\mathrm{Fe}(\mathrm{III})^{5}$ under anaerobic conditions. The microbial influences on uranium and iron chemistries 
suggest that Np speciation may be significantly altered by microbial growth. Significant microbial reduction of $\mathrm{Np}(\mathrm{V})$ would have a marked influence on the fate and transport of this radionuclide in the environment. Based on the literature reports cited above, and our previous experience with the growth of Desulfovibrio desulfuricans ${ }^{6}$, we have chosen to investigate the influence of this sulfate reducing anaerobic bacterium on $\mathrm{Np}$ chemistry.

Table I. The standard reduction potentials of some common metal ions ${ }^{7}$. The more positive the value, the more favored the reaction product.

\begin{tabular}{|l|l|}
\hline Reduction Half-Cell & Potential (V) \\
\hline $\mathrm{UO}_{2}^{2+}+4 \mathrm{H}^{+}+2 \mathrm{e}^{-} \rightarrow \mathrm{U}^{4+}+2 \mathrm{H}_{2} \mathrm{O}$ & +0.27 \\
\hline $\mathrm{NpO}_{2}^{+}+4 \mathrm{H}^{+}+\mathrm{e}^{-} \rightarrow \mathrm{Np}^{4+}+2 \mathrm{H}_{2} \mathrm{O}$ & +0.66 \\
\hline $\mathrm{Fe}^{3+}+\mathrm{e}^{-} \rightarrow \mathrm{Fe}^{2+}$ & +0.771 \\
\hline $\mathrm{Hg}^{2+}+2 \mathrm{e}^{-} \rightarrow \mathrm{Hg}^{0}$ & +0.796 \\
\hline
\end{tabular}

\section{EXPERIMENTS}

D. desulfuricans (ATCC 29577) were grown anaerobically at $30^{\circ} \mathrm{C}$ in Modified Starkey's Medium (ATCC 207) with lactate. Strict precautions were taken to ensure that Fe was excluded from the growth medium. In addition, $\mathrm{Fe}$ is known to facilitate the reduction of neptunyl(V). The solution $\mathrm{pH}$ was adjusted to 6.2 with hydroxide to stabilize pentavalent $\mathrm{Np}$ and to limit hydroxide formation while maintaining an environment suitable for bacterial growth. Neptunyl were added at the time of culture inoculation. Two control experiments were performed: (1) Np was added to uninoculated medium and (2) $\mathrm{Np}$ was added to spent medium. After incubation for 5 days in the presence of $\mathrm{Np}$, motile cells were observed at $400 \mathrm{x}$ using an Olympus phase contrast microscope.

Optical data were obtained on an Olis-converted Cary-14 spectrophotometer. X-ray diffraction data were obtainéd on the filtered precipitates using a Scintag theta-theta

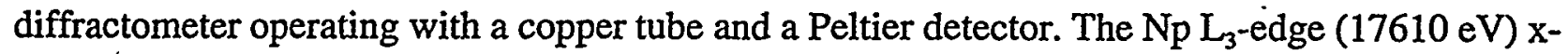
ray absorption near edge structure (XANES) data were collected on 12BM-B, the BESSRC bending magnet beamline at the Advanced Photon Source (APS). The beam line is equipped with $\mathrm{Si}<111>$ crystals in a double-crystal configuration. Harmonic rejection was accomplished using a Pt mirror, set to reject energies higher than about $25 \mathrm{KeV}$. Harmonic rejection at these energies is necessary at the APS because of the relatively high flux of high-energy photons. The energy was calibrated by setting the inflection point of the first derivative from the $\mathrm{Zr} \mathrm{K}$ edge to $17.998 \mathrm{KeV}$. All data were taken in the fluorescence mode, using a flow-type ion chamber detector (The EXAFS Co.), which was purged with xenon and used without slits or a scattering radiation filter. No time-dependent spectral changes were observed over multiple sample scans.

\section{RESULTS AND DISCUSSION}


The sample of interest and the two controls all showed a white precipitate that formed within the first day of incubation at $30^{\circ} \mathrm{C}$. The precipitate made it difficult to quantify microbial growth, however observable motile microbial cells after 5 days of incubation suggests some microbial growth under our experimental conditions. The solutions were all filtered, after which the remaining solute and the precipitate were treated separately. An x-ray powder pattern of the precipitate revealed no diffraction lines. The precipitate appears amorphous at copper-radiation wavelengths.
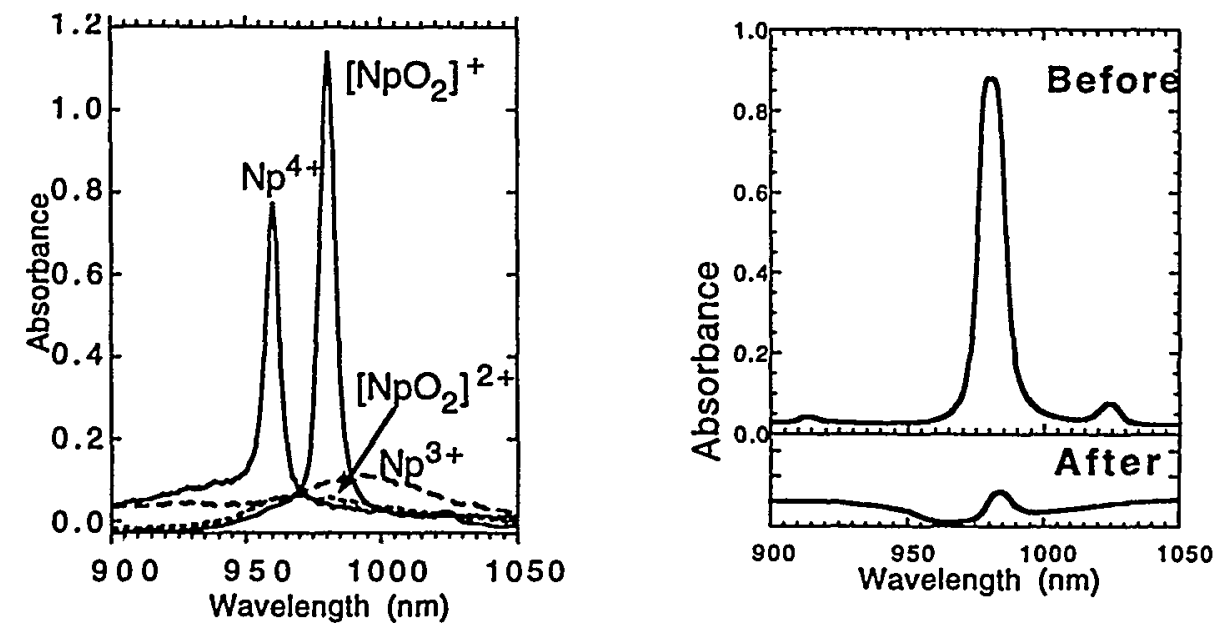

Figure 1. Left: The optical spectra of standard Np solutions containing Np(III), Np(IV), $\mathrm{Np}(\mathrm{V})$ and $\mathrm{Np}(\mathrm{VI})$. Right: Optical spectra of the growth medium immediately after inoculation (top) shows the presence of $\mathrm{Np}(\mathrm{V})$. All solutions after incubation (bottom) continue to show evidence of only $\mathrm{Np}(\mathrm{V})$. The intensity of the signal is much reduced however, indication loss of solution Np.

Optical spectra of the solutions were obtained before and after incubation and filtration. The spectra obtained are compared with standard Np spectra in Figure 1. Optical spectroscopy is often used as a characterization tool for the Np oxidation state in solution because of the well separated signature spectrum available for each oxidation state $^{8}$, as demonstrated in the Figure. The spectrum of the $\mathrm{Np}$ in the growth medium immediately after inoculation with bacteria is consistent with that expected for $\mathrm{Np}(\mathrm{V}) \mathrm{O}_{2}{ }^{+}$. Whereas the spectrum taken on the same sample after incubation and filtration also shows the presence of $\mathrm{Np}(\mathrm{V}) \mathrm{O}_{2}^{+}$, the intensity of the signal is significantly reduced. There is no evidence of $\mathrm{Np}$ (IV) in solution, even though the molar absorptivity of tetravalent $\mathrm{Np}$ is rather high. This result is expected because the solubility of $\mathrm{Np}(\mathrm{IV})$ is low at the $\mathrm{pH}$ of the solution. In contrast, because of the broad spectral feature associated with $\mathrm{Np}(\mathrm{VI})$, the presence of moderate amounts of the neptunyl(VI) moiety cannot be ruled out based on these results alone. Assuming a linear relation between absorbance and concentration (Beer's Law), these data provide evidence that much of the $\mathrm{Np}(\mathrm{V})$ has been removed from solution. The $\mathrm{Np}$ remaining in solution is indistinguishable by optical spectroscopy from that of the original solution, appearing as $\mathrm{Np}(\mathrm{V})$. 
XANES spectroscopy supports this finding. The spectra from the Np solutions obtained from both the active bacteria and the spent medium after filtration indicate the presence of very little Np. In contrast, the precipitates obtained from these samples, as well as the control to which no bacteria were added, all show evidence of significant amounts of $\mathrm{Np}$. The XANES spectra obtained from the solid precipitates are compared with signature XANES spectra of Np in the tri-, tetra-, penta-, and hexavalent oxidation states. XANES is a single ion probe that is very sensitive to oxidation state and has successfully been used to characterize Np speciation ${ }^{9}$, both in solution and in the solid phase. In most cases, the edge energy, defined as the maximum in the first derivative, is seen to shift to higher energy with increasing valence. The situation is somewhat more complex for $\mathrm{U}^{10}, \mathrm{~Np}^{9}$ and $\mathrm{Pu}^{11}$, all of which form the dioxo cations $[\mathrm{O}=\mathrm{An}=\mathrm{O}]^{\mathrm{n}}$. . In these cases, the edge energy does not increase with increasing formal charge on the actinide ion so that any analysis of valence from XANES data must include the edge features to higher energy. This is demonstrated by the Np data from the standard solutions shown in Figure 2. The $\mathrm{Np}(\mathrm{IV})$ and $\mathrm{Np}(\mathrm{V}) \mathrm{O}_{2}{ }^{+}$spectra are similar, and are differentiated in part by the broad peak to higher energy observed for the latter species.

The data obtained from the three solutions are statistically indistinguishable and are represented in Figure 2 by the data from the $\mathrm{Np}$ in the spent medium. The edge energies and the peak shapes from these data are consistent with $\mathrm{Np}(\mathrm{V}) \mathrm{O}_{2}^{+}$in solution. These results directly support the optical data from the same solutions. The data obtained from the solid precipitates are also indistinguishable among themselves. However, they are markedly different from the data obtained from the solutions. The data from all the solid precipitates are consistent with $\mathrm{Np}$ (IV).
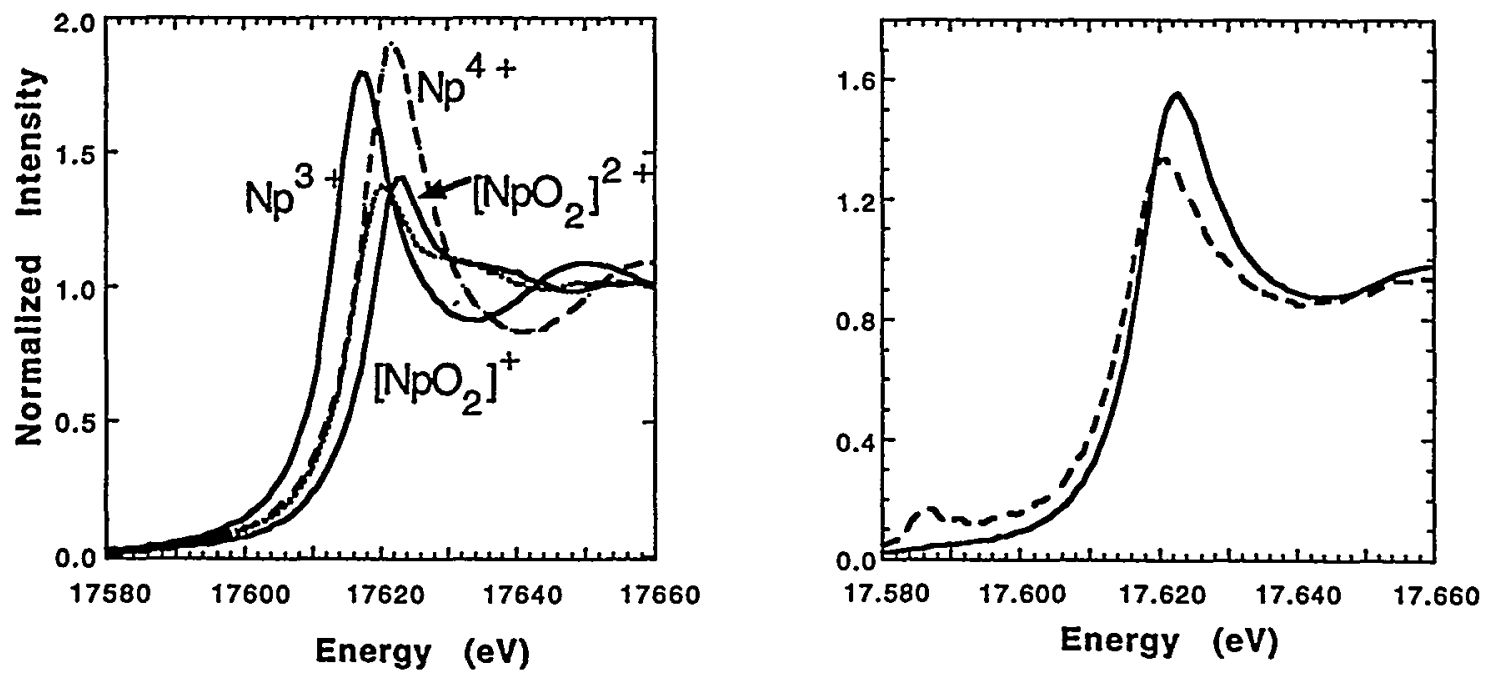

Figure 2. Left: A comparison of the XANES obtained from $\mathrm{Np}$ in 4 different oxidation states. It can be seen from the figure that $\mathrm{Np}(\mathrm{IV})$ and $\mathrm{Np}(\mathrm{V})$ have similar edge positions. Right: A comparison of the XANES spectra obtained from the solution after incubation (dotted line) with that of the solid precipitate (solid line). These XANES data show that Np has been reduced in solution. 
The XANES data clearly demonstrate the presence of $N p(V)$ in solution and $N p(I V)$ in the solid precipitates. The data from the sample in which $\mathrm{Np}$ was added to the culture medium with viable $D$. desulfuricans are indistinguishable from those in which $\mathrm{Np}$ was added to spent medium and from those in which $\mathrm{Np}$ was added to fresh medium without any $D$. desulfuricans. The precipitates formed in all samples at approximately the same rate during incubation. These results show that the reduction of $N p(V)$ to $N p(I V)$ was independent of the presence of $D$. desulfuricans on the timescale of days. $N p(V)$ is rapidly and almost quantitatively reduced in the presence of the medium alone at $30^{\circ} \mathrm{C}$.

The underlying assumption for the experimental protocol chosen herein was that $\mathrm{NpO}_{2}^{+}$ would be stable in the culture medium and that the reduction of $\mathrm{Np}(\mathrm{V})$ would arise primarily from a biotic process, or as a secondary result of a biotic process. This assumption was based in part on the reduction potential listed in Table $I$ for $N p(V)$. This standard reduction potential represents the thermodynamic value obtained with $\mathrm{Np}$ in an acidic solution $(\mathrm{pH}=0)$ of perchloric acid. The culture medium required to grow $D$. desulfuricans differs markedly from this standard solution, and as a result the redox couple is expected to shift to lower potential ${ }^{12}$. Furthermore, the neptunyl(V)/neptunium(IV) couple is not rapidly reversible in perchloric acid, ${ }^{13}$ however the kinetics can be significantly altered by the presence of other ions, such as iron. Perhaps the most important to consider are disproportionation reactions of the form:

$$
2 \mathrm{NpO}_{2}^{+}+4 \mathrm{H}^{+} \Leftrightarrow \mathrm{Np}^{4+}+\mathrm{NpO}_{2}^{2+}+2 \mathrm{H}_{2} \mathrm{O}
$$

Note that this equilibrium reaction is dependent on acid concentration in solution. In the presence of a complexing anion, the equilibrium will be shifted. For example, studies have shown that the equilibrium constant for this reaction is $4 \times 10^{-7}$ in $1 \mathrm{M}$ perchloric acid, but is shifted to $2.4 \times 10^{-2}$ in $1 \mathrm{M}$ sulfuric acid ${ }^{14}$. This shift in equilibrium results in a 10,000 fold increase in the concentration of $\mathrm{Np}^{4+}$, which is insoluble and drops out of solution. Unfortunately, sulfate is an essential component of the medium because $D$. desulfuricans is a sulfate reducing bacterium, that is it derives its energy from the reduction of $\mathrm{SO}_{4}{ } \cdot \mathrm{Np}^{4+}$ hydrolyses readily at the $\mathrm{pH}$ of these experiments, forming an insoluble hydroxide according to ${ }^{1}$ :

$$
\mathrm{Np}^{4+}+\mathrm{nH}_{2} \mathrm{O} \rightarrow \mathrm{Np}(\mathrm{OH})_{\mathrm{n}}^{(4-\mathrm{n})+}+\mathrm{nH}^{+} \text {. }
$$

Finally, it has been previously demonstrated that uranyl is reduced to $\mathrm{U}^{4+}$ oxides or hydroxides under hydrothermal treatment in the presence of an organic monolayer ${ }^{15}, 16$. Iron(III) has been shown to reduce under similar conditions ${ }^{17}$.

Our results, supported by literature precedent, reveal that neptunyl(V) is reduced abiotically under the employed experimental conditions. We have not ruled out some concomitant biotic reduction of neptunyl, however the abiotic pathway is clearly dominant. Attempts to conduct biotic $\mathrm{Np}$ redox experiments in a simplified growth medium may provide further insight into the mechanism of $\mathrm{Np}$ reduction, but they are unlikely to provide insight into the fate of environmental $\mathrm{Np}$ in the presence of $D$. desulfuricans. The experiments discussed herein have demonstrated that the abiotic chemistry is controlling the Np speciation in conditions conducive to $D$. desulfuricans growth. 


\section{ACKNOWLEDGMENTS}

The authors thank Mark Jensen and Jennifer Linton for technical assistance, and James

Sullivan for stimulating conversation. The work at Argonne was supported by the U.S. DOE, BES - Chemical Sciences, under contract W-31-109-ENG-38.

\section{REFERENCES}

1 J. A. Fahey, in The Chemistry of the Actinide Elements, edited by J. J. Katz, G. T. Seaborg and L. R. Morss (Chapman and Hall, London, 1986), Vol. 1, p. Chapter 6.

2 D. R. Lovley, E. J. P. Phillips, Y. A. Gorby, and E. R. Landa, Nature 350, 413-416 (1991).

3 D. R. Lovley and E. J. P. Phillips, Environ. Sci. Technol. 26, 2228-2234 (1992).

4 L. L. Barton, K. Choudhury, B. M. Thomson, K. Steenhoudt, and A. R. Groffman, Radioact. Waste Manag. Enviro. Restor. 20, 141-151 (1996).

5 D. R. Lovley, Microbio. Rev. 55, 259-287 (1991).

6 M. R. Antonio, M. Tischler, and D. Witzcak, (submitted, this conference).

7 A. J. Bard and L. R. Faulkner, Electrochemical Methods: Fundamentals and Applications (Wiley, New York, 1980).

8 P. G. Hagen and J. M. Cleveland, J. Inorg. Nucl. Chem 28, 2905 (1966).

9 L. Soderholm, M. R. Antonio, C.Williams, and S. R. Wasserman, Anal. Chem. 71, 46224628 (1999).

10 E. A. Hudson, J. J. Rehr, and J. J. Bucher, Phys.Rev. B 52, 13815-13826 (1995).

11 A. L. Ankudinov, S. D. Conradson, J. MustredeLeon, and J. J. Rehr, Phys.Rev.B 57, 75187525 (1998).

12 M. Pourbaix, Atlas of electrochemical equilibria in aqueous solutions (Pergamon Press, Oxford, 1966).

13 J. C. Sullivan, D. Cohen, and J. C. Hindman, J. Am. Chem. Soc. 1954, 4275-4279 (1954).

14 B. B. Cunningham and J. C. Hindman, The Actinide Elements, London, 1954).

15 D. M. Giaquinta, L. Soderholm, S. E. Yuchs, and S. R. Wasserman, Radiochim. Acta 76, 113-121 (1997).

16 S. R. Wasserman, L. Soderholm, and D. M. Giaquinta, (submitted this conference).

17 S. Wasserman, L. Soderholm, and U. Staub, Chem. Mater. 10, 559-566 (1998). 